\title{
The preventive treatment of recurrent stone-formation: how can we improve compliance in the treatment of patients with recurrent stone disease?
}

\author{
Dirk Jan Kok ${ }^{1}$
}

Received: 30 July 2015 / Accepted: 5 November 2015 / Published online: 14 December 2015

(C) The Author(s) 2015. This article is published with open access at Springerlink.com

\begin{abstract}
Whether prevention of Urolithiasis is worthwhile is the outcome of the balance between efficacy of prevention and costs and efforts related of respectively prevention and treatment of a new stone. Well controlled trials demonstrate that effective prevention of new stone formation is possible using medical treatment and lifestyle interventions. In long-term general practice the results obtained with preventive interventions is disappointing. Low and diminishing long-term compliance to the intervention is a major cause for this. Both the long-term aspect and the natural resistance to lifestyle changes contribute to this low compliance. From an analysis of the existing data on trials of preventive interventions and from experiences obtained in other patient groups where lifestyle changes are applied I will make the case that self-empowerment of the patient using m-health lifestyle coaching (a smart phone application) can considerably enhance the level of prevention that is obtained in general practice. In conclusion, I will describe what features will improve usage and efficacy of such an app.
\end{abstract}

Keywords Lifestyle $\cdot$ e-health $\cdot \mathrm{m}$-health $\cdot$ Coaching . Stone $\cdot$ Compliance

\section{Introduction}

The considerable improvements of methods for stone removal that occurred the last decades may raise the

Dirk Jan Kok

d.kok@erasmusmc.nl

1 Department of Urology, Erasmus MC, Rotterdam, The Netherlands question if efforts for prevention of recurrent stone formation are worthwhile. In addition there are questions of what are successful interventions and how can patients in general practice be persuaded to adhere long-term to such interventions? In this article, I will put forward arguments that support the need for prevention of stone formation, reasons for the differences in efficacy of prevention between controlled trials and general practice, clarify the special role of patient compliance, defend the potential of E-health for supporting patient compliance and describe the essential features of a mobile phone lifestyle coaching application.

Stone formation is a big problem in numbers of patients with a prevalence of around $10 \%$ in the USA [1] and an increasing incidence $[2,3]$. It also has a high recurrence rate, $27-50 \%$ within 5 years after a first urinary stone when no specific treatment is given $[4,5]$. Given this extent of the problem, researchers have used cost-benefit models to investigate how the costs for prevention, coaching and medication, compared to costs related to stone recurrence, removal and societal costs such as productivity loss. Their conclusion was that the benefits can outweigh the costs [6-11]. It was estimated that for the USA in 1996 medical stone prevention could save $\$ 2158$ per patient per year [8]. In the UK a single large stone center could save up to 250,000 pound per year at 1998 prices by applying a program of metabolic and nutritional risk factors screening followed by appropriate preventive measures [9]. These numbers relate to secondary prevention, aimed at patients with a history of stone formation.

Of course such studies are based on several assumptions regarding for instance the risk reduction that can be obtained with interventions. For the situation in the USA it has been estimated which criteria should be met in order to make primary stone prevention cost effective [10]. The incidence should exceed $1 \%$, prevention should achieve a $50 \%$ risk 
reduction and the yearly cost of prevention should be below US\$20. Further modelling showed what effect patient compliance has on the results obtained with a simple low-cost preventive treatment, keep fluid intake above $2 \mathrm{~L}$ daily [11]. For the total French population cost savings would amount to $€ 49$ million assuming $100 \%$ compliance, the dream of every doctor. Savings would amount to $€ 10$ million when $25 \%$ of all people is compliant, still a big challenge for a long-term lifestyle intervention. In this model compliance was defined as the percentage of a group that complies longterm with the treatment. Maybe equally important will be how consistent the compliance of the individual patient is. Has the treatment become a part of the normal routine or is it something that is remembered occasionally?

How realistic are the criteria that were used in these models and which factors influence them?

The criterium that the incidence should exceed $1 \%$ is easily met. In the USA the incidence is $7 \%$ for women and $13 \%$ for men $[1,6]$.

The second criterion of a $50 \%$ risk reduction is also realistic. A relative risk (RR) of 0.5 has been achieved in several randomized controlled trials of stone preventive interventions, as was recently reviewed [12]. RR values range from 0.06 to 0.61 for pharmacologic interventions and from 0.15 to 0.83 for dietary interventions. Although one study reported an increased risk, RR 5.88, in its intervention group receiving the advice to reduce intake of animal protein and increase intake of fiber [13]. Keeping in mind that the number of RCTs of stone preventive treatment is small and the quality of these trials on average is only fair [12], a $50 \%$ reduction of stone recurrence seems feasible. Which intervention will provide the best preventive results is undecided. Something which is clear is that patient compliance is a key determinant for achieving the level of prevention that is promised by controlled trials also in general practice. In an RCT extra funds and time are available for intensive coaching to increase patient compliance. In the RCTs for stone prevention, patients were reminded at least once and up to six times per year to follow their treatment (Table 1). In general practice with its restrictions for time and money the upper limit for coaching may be once a year. There is a need for tools that allow extra coaching in general practice within the limits of time and funding.

The criterion that costs of prevention must be below US\$20 is a challenge. Of course, the figure was derived using a low estimate for stone incidence of $1 \%$. The actual incidence is higher what will raise the figure. However, this cost factor appears to exclude pharmacologic treatment. This leaves dietary intervention where the costs are dictated by the dietary changes themselves and by the costs of coaching. It is difficult to assess what it will cost to change from a high risk "Western Style" diet (high intake of animal protein and salt, low intake of fruit and vegetables, low water intake) to one of the advised low risk diets (lower intake of animal protein and salt, higher intake of fruit/ vegetables and water, avoiding food with a high oxalate content). Furthermore, this intervention may produce additional societal savings by also lowering the risk for other diseases like those comprised in the metabolic syndrome. In the absence of detailed analysis of this matter I will assume that such changes can be made cost-neutral. This leaves the costs related to the coaching that must accompany lifestyle changes. The approach applied in RCTs, coaching through follow-up visits to the clinic, is very expensive. Again there is a need for low-cost forms of coaching.

Finally the criterion that at least $25 \%$ of the patients must comply with the intervention is also a challenge, especially when it contains elements of lifestyle changes. Kocvara et al. [14] compared the effect of preventive treatment in different medical centers. They confirmed that the patients who showed the lowest compliance to the therapy, as documented by biochemical parameters, had the highest recurrence rate. Comparing the approaches followed in the different centers they concluded that the best compliance was obtained by giving frequent and clear coaching: "the patients find it easier to adhere to a specific dietary regimen than to general instructions." Thus, a combination of specific instructions and frequent repetition of the dietary counselling seems to provide a good reduction in recurrence.

Table 1 Overview of randomized controlled trials on lifestyle intervention for prevention of stone recurrence

\begin{tabular}{|c|c|c|c|c|c|}
\hline Trial & Intervention & Duration & Patient type & Coaching frequency & RR \\
\hline Shuster 1992 [54] & Replace soft-drinks & 35 & $37 \% 1$ st, $63 \%$ rec & 6 year & 0.85 \\
\hline Borghi 1996 [4] & Drinking advice & 60 & 1st with residual fragments & $1+4$ year volume measurement & 0.45 \\
\hline Hiatt 1996 [13] & Low protein & 42 & 1st, no residual fragments & 2 year & 5.88 \\
\hline Kocvara 1999 [14] & Tailored diet & 36 & 1 st, $21 \%$ residual fragments & 1 year vs. 1,3 year control group & 0.32 \\
\hline Borghi 2002 [17] & Low animal protein, low salt & 60 & $\begin{array}{l}\text { Recurrent, } 27 \% \text { residual fragment } \\
\text { explicit wish for dietary intervention }\end{array}$ & $1+4$ year volume measurement & 0.45 \\
\hline Sarica 2006 [55] & Drinking advice & 12 & Recurrent & 2,3 year & 0.15 \\
\hline Dussol 2007 [56] & High fiber/low animal protein & 48 & Recurrent & 3 year & $0.83 / 1$ \\
\hline
\end{tabular}


Data from a 30-year experience of a specialized stone clinic in Chicago show that at best one can retain 70-80\% of patients at each follow up cycle [15]. This required an initial 6-week follow up with 24-h urine collection and subsequent yearly coaching by two physicians based on reanalysis of stone risk factors. Thus even in this dedicated stone clinic setting with a relatively high input of manpower the interest of patients to stay involved with their disease management is rapidly declining. On top of that it is not ensured that the success cases, that is patients who do return, actually adhere stringently to the treatment. In this respect it would help if coaching tools not only stimulate but also register compliance for feedback to both the patient and the doctor.

Overall it appears that low-cost tools for patient coaching and for feedback to the doctor are needed. E- and $\mathrm{m}$-health might provide the needed level of coaching at low cost.

Since a major rationale for using such tools will be to improve patient compliance it is worthwhile to further define the factors that affect patient compliance.

\section{Patient compliance to stone preventive treatment}

Compliance is co-determined by the patient's motivation. The experience of colic pain can be a good motivator at start. When patients after experiencing a stone episode were asked if they would consider taking medication daily to prevent recurrent pain or a surgical procedure the majority answered yes [16]. In contrast, most of the urologists that were interviewed thought that patients would prefer to avoid medication even in the face of new stone events. The RCT results show that live coaching at a frequency of 1-6 times per year may maintain motivation at a level that delivers the desired risk reduction (Table 1). In general practice some self-coaching tools have been used to support especially the "drinking" advice that is routinely given to patients. One is to ask patients to measure their urine volume every 3 months $[4,17]$. The second type of self-coaching is to tell the patient to look at the color of the urine and to drink more when the urine is very dark (ReisSantos, Lisbon personal communication).

Coaching of dietary advice is more complicated as the dietary advice itself is complex. One mechanism by which dietary advice lowers the risk for stone recurrence is by decreasing the driving force for stone formation, supersaturation. The classic players in this are calcium, oxalate, uric acid, urine $\mathrm{pH}$ and volume. A decrease in the urine concentrations of calcium and oxalate and a combination of low urine uric acid concentration plus high enough urine $\mathrm{pH}$ lower the risk for calcium oxalate stone formation respectively uric acid stone formation. A first problem is that the urine values are the end result of the cascade of intake, uptake and metabolism-related renal actions. Patients must understand that the intakes of calcium and oxalate effect each-others uptake. Then there is the indirect player, the acid-base balance that amongst others governs urine citrate excretion [18]. A high protein diet provides an acid load which increases the risk of stone formation by decreasing citrate excretion and decreasing inhibition of calcium oxalate crystal agglomeration [19, 20]. Here the information which must be conveyed to the patient becomes even more complicated. The acid-base balance has two dietary sides, dietary acid load and dietary alkali load, plus an individual component, the body size related intrinsic production of acid [21]. Dietary acid load is largely related to protein consumption. Dietary alkali load is largely provided by fruits and vegetables which are sources for organic acids from which bicarbonate can be produced [21]. Thus drinking orange juice, which is acid by itself, provides an alkali source for the human body. Again this is a difficult message to convey. Then there are those food items that on the one hand decrease the risk for stone formation, because they increase urine volume (tea) or are a source of alkali (spinach), while on the other hand, they increase the risk for stone formation by providing extra oxalate. To complicate things further it is advised to consume normal amounts of calcium, a stone component, because it binds oxalate in the gut and thereby lowers crystallization risk in the urine. Many students of medicine cannot reproduce this knowledge correctly in exams taken 1 month after being told this.

This complexity is reflected in the sometimes conflicting data from intervention trials where individual risk factors are singled out. Possibly the least bias is obtained in observational studies of subjects who follow their free choice lifestyle. Several large observational studies are available to show how a low-risk lifestyle could look like [3, 22-24]. The risk for kidney stone formation was found to increase with increasing meat consumption and to decrease with increasing consumption of fresh fruit, fibre from wholegrain cereals and magnesium [24]. In study [24] the hazard ratio was 0.80 in moderate meat eaters ( 74 and $74 \mathrm{~g} /$ day), 0.52 in low meat-eaters ( 30 and $28 \mathrm{~g} /$ day), 0.73 in fish eaters and 0.69 in vegetarians when compared to the cohort with the highest intake of meat (median $135 \mathrm{~g} /$ day for men and $127 \mathrm{~g}$ /day women). One mechanism to explain these relations may be linked to the acid/base balance of the diet. Table 2 shows the difference in acid load provided by the diets of the different groups in the Turney study, estimated using the approach detailed in [21]. The high meat consumption group is taken as reference for calculating Hazard ratio and acid load difference. Clearly in this study a lower meat intake yields a lower potential renal acid load and a Hazard ratio below 1. Finally, a reduced risk of incident kidney stones during 8 years follow-up was also linked to 
Table 2 Net acid load of diets described in [24] plus hazard ratio for stone formation

\begin{tabular}{lccccl}
\hline High meat & Moderate meat & Low meat & Fish & \multicolumn{2}{l}{ Vegetarian } \\
\hline 1.66 & -0.61 & -2.25 & -4.68 & -8.64 & Men \\
-0.87 & -2.84 & -4.56 & -6.72 & -9.76 & Women \\
1 & 0.8 & 0.52 & 0.73 & 0.69 & HR \\
\hline
\end{tabular}

The values for net acid load represent the difference compared to the high meat diet. A negative value denotes less acid (more alkaline) diet

a greater intake of fiber, fruits and vegetables in a study on 83,922 postmenopausal women [24]. However this study could not confirm this relation for women with a history of stones [25]. An explanation for this may be that the other side of the acid-base balance, the intake of meat and fish, which was not reported in this study, mitigated the alkalinizing effect. The other way around the fact that other epidemiologic studies do no support a relation between a high protein intake and an increased risk for stone formation $[23,26,27]$ may be related to mitigation of the acid load provided by protein through an alkali load provided by fruit and vegetables. Finally, complicating all these studies is the fact that there is an intrinsic renal acid load produced by normal metabolism. This production increases with body weight. Increased intrinsic acid production is involved in the relation between obesity and the risk for stone formation $[22,28]$. Overall, the focus should be on all aspects of the acid-base balance.

In intervention studies a reduction of the intake of animal protein in combination with a drinking advice has been shown to decrease stone recurrence when compared to patients following a low calcium diet plus the advice to drink more [17]. However, the combination of an advice to reduce animal protein with the advice to maintain an adequate urine volume does not reduce recurrence significantly compared to a drinking advice alone.

Overall the trial data obtained up to now provide some support for the contention that a combination of dietary advice including acid-base balance and intakes of calcium oxalate and salt plus the advice of maintaining a high urine volume may reduce stone recurrence and that the efficacy of the prevention is dictated by patient compliance.

\section{How can we improve patient compliance to stone preventive therapy?}

As outlined above what is needed are tools that provide coaching for taking medication but especially for adapting a desired lifestyle. E- and m-health applications are an option. When constructing such tools it must be kept in mind that the goal is to increase the compliance of the patient to a lifestyle with a low risk for stone formation. Thus the tools must provide correct, detailed, personalized information in a manner that stimulates the patient to actually use the tool.

For the purpose of lowering the risk for stone formation they should provide the user a detailed analysis of the actual diet including water intake with a focus on known risk elements, a comparison versus a diet that poses a low risk for stone formation, advice on improvements, background information on the risk factors for stone formation and a long-time overview. It should also take into account the effects of physical activity and sweat loss, the effect of body size and the effect of the environmental ambient temperature [28]. Finally the analysis should also deal with the complexities that can occur with dietary advice as mentioned before.

Thus, the message that these tools must convey contains seemingly conflicting aspects. Patients are advised to not overconsume foods with a high content of oxalate, including a short list of fruits, vegetables and tea, and at the same time to increase the intake of fruits and vegetables because of their alkalinizing property and to drink enough. What if you want to drink tea? Why is protein an acid load while fruit juice with a low $\mathrm{pH}$ poses an alkali load? Furthermore it is told that sweat loss, related to physical activity and ambient temperature, is a risk as it can lower urine volume [29]. On the other hand, data suggest that physical activity reduces the risk for stone formation, possibly because it leads to a lower body weight [30]. The fact that this association between a high physical activity and lower incidence of symptomatic kidney stones could not be confirmed when analyzing three large prospective cohorts [31] may be due to the fact that the risk is mitigated when the sweat loss is compensated by taking extra fluid. How well does the existing supply of E- and m-health tools that aim to support prevention of urolithiasis work in this respect?

As reviewed in this journal recently as of 2014 more than 42 smart phone apps could be found that aim to coach towards lowering the risk for stone formation [32]. Most were designed by patients, a few by health professionals. This development of smart phone apps is still in the early unstructured phase. Most tools provide information to patients or medical professionals, a few provide the option to register the daily intake of water or calcium and some provide suggestions on a low-risk lifestyle. None provide a complete package of lifestyle analysis comprising all risk factors plus up-to date information plus coaching plus feedback to both the patient and the doctor. A few are constructed based on evidence-based information but some provide advice that goes against the current bestpractice, like lowering calcium intake. None provide all features that are needed to entice patients to adapt a low risk lifestyle as their lifestyle of free choice. The authors 
of the review recommend "improving the usefulness of these apps by seeking a 'quality stamp' from recognized urological organizations and greater clinician involvement in future app development." I concur with this statement and would add that in urolithiasis app development there should be two aims: a complete approach as outlined above and a focus on user-friendliness in order to obtain maximal compliance to both using the app and following a low risk lifestyle. For the latter aspect lessons can be learned from behavioral science.

\section{Coaching by apps, lessons from behavioral science}

Many major chronic diseases including urolithiasis and the other diseases grouped under the denominator metabolic syndrome [33] benefit from interventions that target nutrition and physical activity. Although the details of the advice may vary all these interventions in fact try to entice people to follow a balanced lifestyle. All face the same problem of how to approach someone for changing his or her lifestyle. Much can thus be learned from the experiences obtained with patients with renal disease, obesity or even of the general public [34-39]. In addition it must be recognized that a group of urolithiasis patients is a mix of people with a high motivation to start with prevention advice, those who recently experienced a stone event, and of people for whom the memory of the colic pain has faded. The latter must in fact be approached like any other member of the general public with the experience of the stone event being a dormant motivator.

Comparison of interventions aimed at different groups reveals several common "success-features" [39]. One feature is to provide self-management instead of a topdown approach where experts tell subjects what to do
[40]. Self-management was found to enhance the results obtained with web-based interventions at the workplace [41, 42]. Examples of self-management for urolithiasis prevention are regularly measuring one's urine volume and looking at the urine color. Addition of computer aided behavioral change to existing health care consultation can also stimulate self-management and thereby increase the effectivity of the intervention, and can be cost effective but improvement is needed [42-47]. One of the problems that remains to be solved is that usage of the app must not be a barrier by itself. To ensure this the app must adhere to two sets of requirements.

The first set, shown in Fig. 1, concerns the elements which ensure that the app provides the user advice and coaching that is individualized towards their disease status (type of stone, recurrence rate, aberrant urine composition), personality, capacities, current (preferred) lifestyle and social and physical environment. The user characteristics depicted in Fig. 1 relate to intrinsic motivation, internal locus of control (beliefs towards health) and self-efficacy, social norms and support. Personalization of intervention programs towards these user characteristics is key for compliance and change-maintenance. Historically it was thought that lifestyle change requires a mix of motivation, facts, education, action and will power. Once motivated, facts would lead a person to a behavior change that was sustained by periodically re-visiting the facts. It, however, became clear that the induced behavior varies with the individual's attitudes towards behavior, subjective norms and perceived behavioral control [48]. A parallel may be drawn to experiences with shared decision making. Here patients are asked to participate in the clinical decisions regarding the course of their treatment. A review of the literature on this topic shows that while most efforts have been put in the segment of information provision towards the patient,

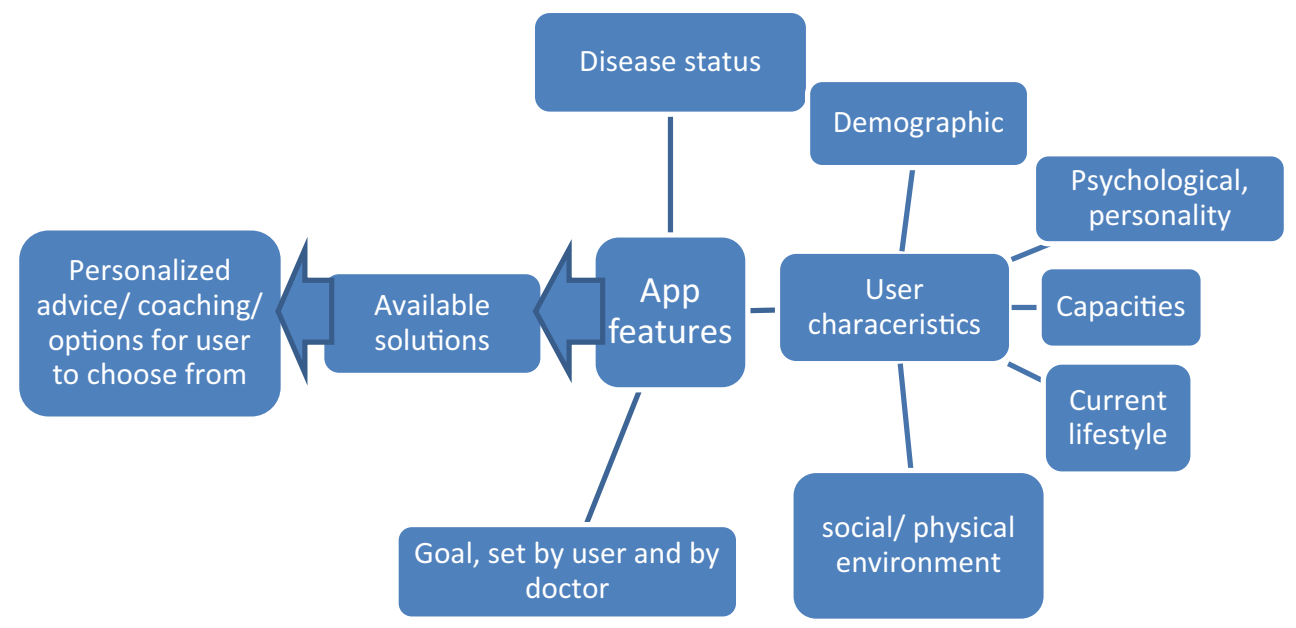

Fig. 1 Elements that determine the functional design of a smart phone app 


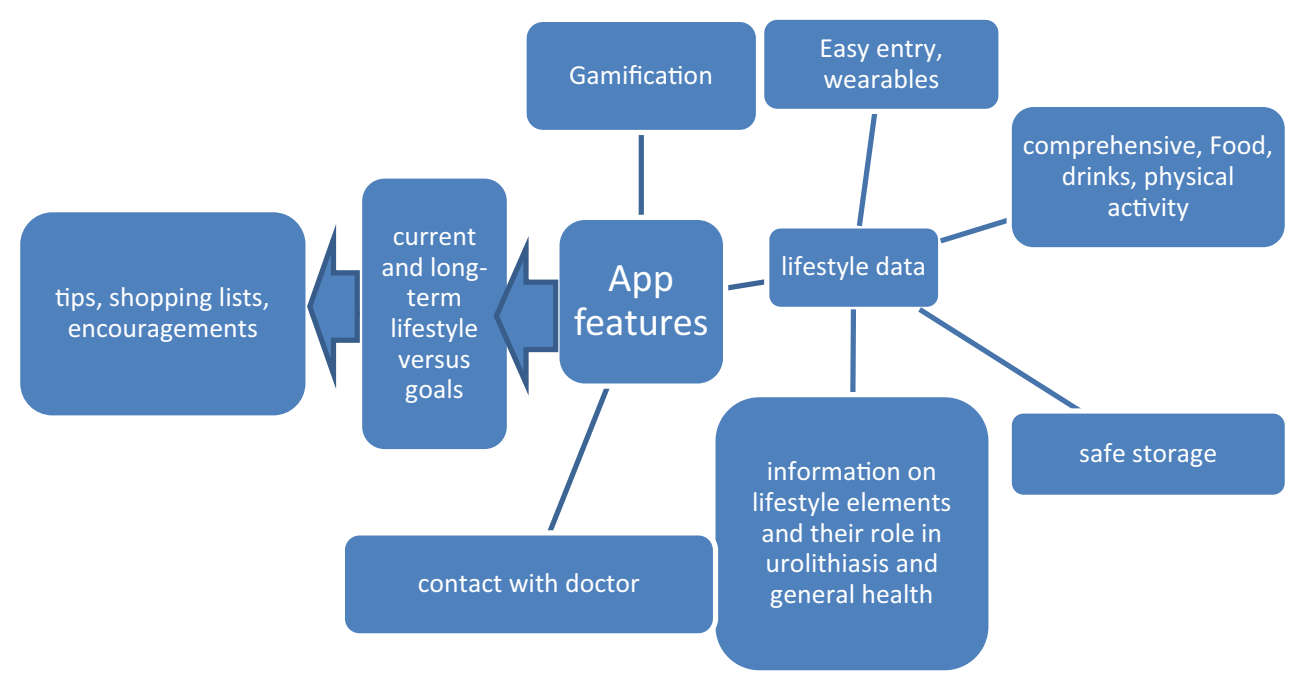

Fig. 2 Interface design of a urolithiasis smart phone app

a neglected barrier is the perception of the patient of really having power to steer the decisions and the standpoint: "the doctor knows best and I am not equipped to make treatment decisions" [49]. Thus while compliance is supported by providing patients free-choice options it is hindered by the inherent uncertainty if the choices are correct. The coaching tool must convince patients that they can make their own correct choices.

Keywords are thus a person's 'readiness' to take action, self-efficacy and perceived barriers [41, 42, 50]. When a population is asked to adapt their lifestyle, only $15 \%$ is ready and willing to start, $40 \%$ is not ready yet and the remainder is even more difficult to convince. Lifestyle adaptation programs that focus on advice content tend to reach mainly the easy $15 \%$. Customization and intensive coaching are needed to reach also the next $40 \%$ let alone the rest.

Finally, a barrier can also exist on the side of the clinician. Again, a review of the field of shared decision making shows that an important barrier for the implementation of patient decision support tools is indifference on the part of health care professionals who may show less confidence in the content of the advice and have concerns about disruption to established workflows [51]. One suggestion to improve clinician compliance was to provide incentives that reward the use of these interventions. Coaching tools should also benefit the clinician. Benefits could be easy access to long-term lifestyle data and analysis collected by the patient.

Other app features concern the goals set by the doctor and the user. These must on one hand adhere to the most up-to-date evidence based knowledge and support the view of the clinician and on the other hand be flexible enough to meet the individual preferences. For instance advising a patient to eat less meat may be beneficial from a methodological view but will not be efficient when the patient does like to eat meat and consequently has a low compliance to the advice. In this case the better approach might be to provide the option of balancing meat intake with fruit/vegetable intake.

\section{Requirements for the development of a urolithiasis prevention app}

The total set of requirements depicted in Fig. 1 ensures that the user is coached towards an individually determined optimal lifestyle solution.

The experience with patients undergoing renal transplantation may serve as an example. These patients gain weight after transplantation, often becoming overweight or obese. Probable causative factors are a return of appetite, slow return of physical activity, side effects of immune suppressive agents (including appetite for fat) [46]. Furthermore there is individual variation in the risk for weight gain. It is higher in women, in patients with a low economic position, in specific ethnic groups and in people aged $>50$, [50]. Weight gain in post TX patients can be reduced with changes in diet (negative caloric balance), physical activity and behavior (individual and group-coaching to stimulate, e.g. compliance, coping capacity $[36,52,53]$. A combination of all three plus a high coaching intensity produces the best results, especially when the intervention applies both knowledge transfer (tailored to the individual) and selfteaching $[33,36,37]$.

The second set of app features shown in Fig. 2 concerns the app interface and usability. The app must be used at least until the desired lifestyle is no longer felt to be an 
intervention but has become the natural lifestyle. Data entry must be comprehensive, covering the complete lifestyle but at the same time easy. This is a difficult combination. For registration of physical activity communication of the app with a wearable can be an option. For entry of diet the best balance must be found between completeness of the data (requiring separate entry of all food items that were contained in meals) and ease (entry of complete meals with an estimation on their average composition). Of course the data storage, needed to provide long-term overviews, must be safe. An extra option may be that the app provides a channel for contact with the doctor. Gamification aspects geared to the individual's social and demographic status may stimulate the use of the app. Finally the advice should be practical, including shopping lists, tips for meals and physical activity and should provide encouragement.

In conclusion, prevention of stone recurrence can be accomplished, coaching patients towards maintaining a high compliance to a low-risk lifestyle is a key factor and new E- and m-health may provide the needed additional coaching.

\section{Compliance with ethical standards}

Conflict of interest The Erasmus MC is co-owner of a smart phone app for lifestyle coaching that will be released in 2016 .

Open Access This article is distributed under the terms of the Creative Commons Attribution 4.0 International License (http://creativecommons.org/licenses/by/4.0/), which permits unrestricted use, distribution, and reproduction in any medium, provided you give appropriate credit to the original author(s) and the source, provide a link to the Creative Commons license, and indicate if changes were made.

\section{References}

1. Stamatelou KK, Francis ME, Jones CA, Nyberg LM, Curhan GC (2003) Time trends in reported prevalence of kidney stones in the USA: 1976-1994. Kidney Int 63:1817-1823

2. Romero V, Akpinar H, Assimos D (2010) Kidney stones: a global picture of prevalence, incidence, and associated risk factors. Rev Urol 12:e86-e96

3. Turney BW, Reynard JM, Noble JG, Keoghane SR (2012) Trends in urological stone disease. BJU Int 109:1082-1087

4. Borghi L, Meschi T, Amato F et al (1996) Urinary volume, water and recurrences in idiopathic calcium nephrolithiasis: a 5 year randomized prospective study. J Urol 155:839-843

5. Ljunghall S, Danielson BG (1984) A prospective study of renal stone recurrence. B J Urol 56:122-124

6. Pearle MS, Calhoun EA, Curhan GC (2005) Urologic diseases of America project. Urologic diseases in America project: urolithiasis. J Urol 173:848-857

7. Saigal C, Joyce G, Timilsina A, Project UDiA (2005) Direct and indirect costs of nephrolithiasis in an employed population: opportunity for disease management? Kidney Int 68:1808-1814

8. Parks JH, Asplin JR, Coe FL (2001) Patient adherence to longterm medical treatment of kidney stones. J Urol 166:2057-2060
9. Robertson WG (2006) Is prevention of stone recurrence financially worthwhile? Urol Res 34:157-161

10. Lotan Y, Pearle MS (2011) Cost-effectiveness of primary prevention strategies for nephrolithiasis. J Urol 186:550-555

11. Lotan Y, Buendia Jiménez I, Lenoir-Wijnkoop I et al (2013) Increased water intake as a prevention strategy for recurrent urolithiasis: major impact of compliance on cost-effectiveness. J Urol 189:935-939

12. Fink HA, Wilt TJ, Eidman KE et al (2013) Medical management to prevent recurrent nephrolithiasis in adults: a systematic review for an American College of Physicians Clinical Guideline. Ann Intern Med 158:535-543

13. Hiatt RA, Ettinger B, Caan B et al (1996) Randomized controlled trial of a low animal protein, high fiber diet in the prevention of recurrent calcium oxalate kidney stones. Am J Epidem 144:25-33

14. Kocvara R, Plasgura P, Petrik A et al (1999) Dvoracek J. A prospective study of nonmedical prophylaxis after a first kidney stone. BJU Int 84:393-398

15. Parks JH, Coe FL (1996) The financial effects of kidney stone prevention. Kidney Int 50:1706-1712

16. Bensalah K, Tuncel A, Raman JD et al (2009) How physician and patient perceptions differ regarding medical management of stone disease. J Urol 182:998-1004

17. Borghi L, Schianchi T, Meschi T et al (2002) Comparison of two diets for the prevention of recurrent stoned in idiopathic hypercalciuria. New Eng J med 346:77-84

18. Curhan GC, Willett WC, Speizer FE, Spiegelman D, Stampfer MJ (1997) Comparison of dietary calcium with supplemental calcium and other nutrients as factors affecting the risk for kidney stones in women. Ann Intern Med 126:497-504

19. Turney BW, Appleby PN, Reynard JM et al (2014) Diet and risk of kidney stones in the Oxford cohort of the European Prospective Investigation into Cancer and Nutrition (EPIC). Eur J Epidemiol 29:363-369

20. Kok DJ, Papapoulos SE, Bijvoet OLM (1990) Crystal agglomeration is a major element in calcium oxalate urinary stone formation. Kidney Int 37:51-56

21. Kok DJ, Iestra J, Doorenbos C, Papapoulos SE (1990) The effects of dietary excesses in animal protein and in sodium on the composition and the crystallization kinetics of calcium oxalate monohydrate in urines of healthy men. J Clin Endocrinol Metab 71:861-867

22. Taylor E, Stampfer M, Curhan G (2005) Obesity, weight gain, and the risk of kidney stones. JAMA 293:455-462

23. Taylor E, Fung T, Curhan G (2009) DASH-style diet associates with reduced risk for kidney stones. J Am Soc Nephrol 20:2253-2259

24. Curhan G, Willett W, Knight E, Stampfer M (2004) Dietary factors and the risk of incident kidney stones in younger women: nurses' Health Study II. Arch Intern Med 164:885-891

25. Sorensen MD, Chi T, Shara NM et al (2014) Activity, energy intake, obesity, and the risk of incident kidney stones in postmenopausal women: a report from the Women's Health Initiative. J Am Soc Nephrol 25:362-369

26. Remer T (2000) Influence of diet on acid-base balance. Semin Dial 13:221-226

27. Curhan G, Willett W, Rimm E, Stampfer M (1993) A prospective study of dietary calcium and other nutrients and the risk of symptomatic kidney stones. N Engl J Med 328:833-838

28. Sorensen MD, Hsi RS, Chi T et al (2014) Women's Health Initiative Writing Group. Dietary intake of fiber, fruit and vegetables decreases the risk of incident kidney stones in women: a Women's Health Initiative report. J Urol 192:1694-1699

29. Park HK, Bae SR, Kim SE et al (2015) The effect of climate variability on urinary stone attacks: increased incidence associated 
with temperature over $18^{\circ} \mathrm{C}$ : a population-based study. Urolithiasis 43:89-94

30. Kok DJ (2012) Metaphylaxis, diet and lifestyle in stone disease. Arab J Urol 10:240-249

31. Rodgers AL, Greyling KG, Noakes TD (1991) Crystalluria in marathon runners. III. Stone-forming subjects. Urol Res 19:189-192

32. Ferraro PM, Curhan GC, Caan B et al (2015) Physical activity, energy intake and the risk of incident kidney stones. J Urol 193:864-868

33. Stevens DJ, McKenzie K, Cui HW, Noble JG, Turney BW (2015) Smartphone apps for urolithiasis. Urolithiasis 43:13-19

34. Pettman TL, Buckley JD, Misan GM, Coates AM, Howe PR (2009) Health benefits of a 4 month group-based diet and lifestyle modification program for individuals with metabolic syndrome. Obes Research and Clinical Pract 3:221-235

35. Cooper JN, Columbus ML, Shields KJ et al (2012) Effects of an intensive behavioral weight loss intervention consisting of caloric restriction with or without physical activity on common carotid artery remodeling in severely obese adults. Metab Clin Exp 61:1589-1597

36. Chan W, Bosch JA, Jones D et al (2014) Obesity in kidney transplantation. J Ren Nutr 24:1-12

37. Magnee T, Burdorf A, Brug J et al (2013) Equity-specific effects of 26 Dutch obesity-related lifestyle interventions. Am J Prev Med 44:e57-e66

38. Unick JL, Beavers D, Bond DS et al (2013) The long-term effectiveness of a lifestyle intervention in severely obese individuals. Am J Med 126:236-242

39. Ritz E (2005) Lifestyle modification and progressive renal failure. Nephrology 10:387-392

40. Johnson JL, Prochaska JO, Paiva AL et al (2013) Advancing bodies of evidence for population-based health promotion programs: randomized controlled trials and case studies. Popul Health Manag 16:373-380

41. Kooijmans H, Post MW, van der Woude LH et al (2013) Randomized controlled trial of a self-management intervention in persons with spinal cord injury: design of the HABITS (Healthy Active Behavioural Intervention in SCI) study. Disabil Rehabil 35:1111-1118

42. Robroek SJ, Brouwer W, Lindeboom D, Oenema A, Burdorf A (2010) Demographic, behavioral and psychosocial correlates of using the website-component of a worksite physical activity and healthy nutrition promotion program: a longitudinal study. J Med Int Res 12:e44

43. Robroek SJ, Lindeboom DEM, Burdorf A (2012) Initial and sustained participation in an Internet-delivered long-term worksite health promotion program on physical activity and nutrition. $\mathrm{J}$ Med Internet Res 14:e43
44. Rongen A, Robroek SJW, van Ginkel W et al (2014) Barriers and facilitators for participation in health promotion programs among employees: a 6 months longitudinal study. BMC Public Health 14:573

45. Rongen A, Robroek SJW, Burdorf A (2014) The importance of internal health beliefs for employees' participation in health promotion programs. Prev Med 67:330-334

46. Rongen A, Robroek SJW, van Ginkel W et al (2014) How do needs and preferences of employees influence participation in health promotion programs? A 6 months longitudinal study. BMC Public Health 15:1277

47. Davies CA, Spence JC, Vandelanotte C, Caperchione CM, Mummery WK (2012) Meta-analysis of internet-delivered interventions to increase physical activity levels. Int J Behav Nutr Phys Act 9:52

48. Lustria ML, Noar SM, Cortese J et al (2013) A meta-analysis of web-delivered tailored health behavior change interventions. J Health Commun 18:1039-1069

49. Ajzen I, Madden TJ (1986) Prediction of goal directed behaviour: attitudes, intentions and perceived behavioral control. J Exp Soc Psychol 15:173-189

50. Joseph-Williams N, Elwyn G, Edwards A (2014) Knowledge is not power for patients: a systematic review and thematic synthesis of patient-reported barriers and facilitators to shared decision making. Patient Educ Couns 94:291-309

51. Sharma M, Romas JA (2012) Theoretical Foundations of Health Education and Health Promotion. Jones and Bartlett Learning, London

52. Elwyn G, Scholl I, Tietbohl C, Mann M, Edwards AG, Clay C, Légaré F, van der Weijden T, Lewis CL, Wexler RM, Frosch DL (2013) "Many miles to go ...": a systematic review of the implementation of patient decision support interventions into routine clinical practice. BMC Med Inform Decis Mak 13:S14

53. Portnoy DB, Scott-Sheldon LA, Johnson BT, Carey MP (2008) Computer-delivered interventions for health promotion and behavioral risk reduction: a meta-analysis of 75 randomized controlled trials, 1988-2007. Prev Med 47:3-16

54. Shuster J, Jenkins A, Logan C et al (1992) Soft drink consumption and urinary stone recurrence: a randomized prevention trial. J Clin Epidemiol 45:911-916

55. Sarica K, Inal Y, Erturhan S, Yag ci F (2006) The effect of calcium channel blockers on stone regrowth and recurrence after shock wave lithotripsy. Urol Res 34:184-189

56. Dussol B, Iovanna C, Rotily M et al (2008) A randomized trial of low-animal-proteinor high-fiber diets for secondary prevention of calcium nephrolithiasis. Nephron Clin Pract 110:c185-c194 